\title{
Native and Recombinant Human Hepatocyte Growth Factors are Highly Potent Promoters of DNA Synthesis in both Human and Rat Hepatocytes
}

\author{
Alastair J. Strain, * Tariq Ismail, * Hirohito Tsubouchi, ${ }^{*}$ Naokatu Arakaki," Tadashi Hishida," \\ Naomi Kitamura," Yasushi Daikuhara," and Paul McMaster* \\ ${ }^{*}$ Liver Unit, Queen Elizabeth Hospital, Birmingham B15 2TH, UK; ${ }^{\ddagger}$ Second Department of Internal Medicine, Faculty of Medicine, \\ Kagoshima University, Kagoshima 890; "Mitsubishi Kasei Corporation, Yokohama 227; 'Institute for Liver Research, Kansai Medical \\ University, Osaka, 570; and 'Department of Biochemistry, Kagoshima University Dental School, Kagoshima 890, Japan
}

\begin{abstract}
Human hepatocyte growth factor (hHGF) has recently been expressed as a recombinant polypeptide from Chinese hampster ovary cell transfectants. Using a primary rat hepatocyte bioassay, we have tested the biological activity of recombinant hHGF and compared it with native hHGF. Dose-response curves were almost identical, with half-maximal stimulation of DNA synthesis at 1-2 $\mathrm{ng} / \mathrm{ml}$ (equivalent to $\sim 10 \mathrm{pM}$ ). S-phase labeling index was similarly enhanced and numerous mitotic cells were observed. Recombinant and native hHGF also stimulated DNA synthesis and S-phase labeling index in primary adult human hepatocytes. Human cells were more responsive than rat hepatocytes, with recombinant hHGF slightly more potent than native hHGF (half-maximal stimulation 0.3 and $0.6 \mathrm{ng} / \mathrm{ml}$, respectively). Since HGF levels rise in patients with fulminant hepatic failure and in animals after partial hepatectomy or administration of hepatotoxins, situations where liver regeneration occurs, HGF is suggested to play a key role in regulation of hepatic growth. The high potency of the factor on human hepatocytes reinforces its candidacy as a critical mitogen in human liver growth. The availability of a recombinant hHGF opens the way for in vivo experimental studies and to the possibility of using hHGF as a clinical therapeutic agent, either alone or in combination with other factors. (J. Clin. Invest. 1991. 87:1853-1857.) Key words: hepatic regeneration - fulminant hepatic failure $\bullet$ liver disease $\bullet$ human hepatocytes $\bullet$ recombinant human hepatocyte growth factor
\end{abstract}

\section{Introduction}

Human hepatocyte growth factor (hHGF) ${ }^{1}$ is a polypeptide of mol wt $\sim 85,000-90,000$ first identified in the plasma of pa-

A preliminary account of this work was presented at the 3-6 November 1990, 41 st annual meeting of the American Association for the Study of Liver Diseases, Chicago, IL.

Address correspondence and reprint requests to Dr. Alastair J. Strain, Liver Research Laboratories, Queen Elizabeth Hospital, Edgbaston, Birmingham B15 2TH, England.

Received for publication 10 December 1990.

1. Abbreviations used in this paper: FHF, fulminant hepatic failure; hHGF, human hepatocyte growth factor; HPTA, hepatopoeitin A; KRB, Krebs ringer bicarbonate buffer.

J. Clin. Invest.

(c) The American Society for Clinical Investigation, Inc.

$0021-9738 / 91 / 05 / 1853 / 05 \$ 2.00$

Volume 87, May 1991, 1853-1857 tients with fulminant hepatic failure (FHF) and found to stimulate DNA synthesis in adult rat hepatocytes $(1,2)$. We have recently cloned the factor and reported the deduced 728 amino acid sequence which includes a putative amino terminal signal peptide (3). Nakamura et al. also recently cloned hHGF cDNA yielding a sequence that differed by 14 amino acids (4). hHGF is translated from a full length mRNA of $\sim 6 \mathrm{~kb}$, with a single protease cleavage site yielding two polypeptide chains of mol wt $\sim 30,000$ and 60,000 linked by probably one disulphide bridge $(3,4)$. Rat HGF has also recently been cloned and sequenced $(5,6)$ and a partial amino acid sequence of the rabbit-derived hepatopoeitin A (HPTA) reported (7), indicating close species homology between these factors.

We have shown a direct correlation between circulating levels of hHGF as measured by rat hepatocyte bioassay and the grade of hepatic encephalopathy in patients with $F H F(8)$. Notably, the level was reduced to near normal in patients who had recovered from the disease (8). More recently, using a highly specific ELISA technique, these findings have been confirmed indicating a 30 -fold rise in circulating hHGF in the FHF group (9). The tissue responsible for synthesis and release of this activity however is not known. Although increases were seen in other patient groups such as acute hepatitis, the differences ( $<2$-fold) were small when compared with the large increase seen in FHF (9).

In experimental animals, HGF expression has been found in a variety of tissues including the liver, but some species differences in the pattern of expression are reported $(5,10)$. Serum levels of HGF/HPTA rise after partial hepatectomy in the rat $(11,12)$, although the major sites of synthesis and release during liver regeneration have not yet been identified. However, HGF does rise in the damaged liver tissue of rats after administration of D-galactosamine or $\mathrm{CCl}_{4}(6,13)$. Thus, raised levels of HGF appear to be associated with conditions where after surgical resection or massive acute hepatic damage the requirement for hepatic regeneration is likely to be high.

While a wide range of hormones and growth factors have been implicated in the regulation of liver regeneration in vivo (14), the role of HGF has yet to be fully characterized. In vitro studies from several laboratories indicate HGF to be a potent growth promoter of rat hepatocytes and to act through a unique plasma membrane receptor $(2,15)$. To further examine its relevance as a physiological hepatotrophic factor, in this study, we report the successful expression of recombinant hHGF and compare its potency with purified native hHGF using rat hepatocytes. Additionally, we have compared growth promoting bioactivity of the two HGF preparations on normal adult human hepatocytes. 


\section{Methods}

Preparation of native $h H G F$. Native hHGF was purified from the plasma of patients with fulminant hepatic failure as previously described $(1,2)$. The purified preparations were dissolved in $0.42 \mathrm{M}$ sodium phosphate buffer ( $\mathrm{pH} 7.1$ ) containing $0.15 \mathrm{M} \mathrm{NaCl}$ and $0.013 \%$ Triton X-100 and were kept at $-20^{\circ} \mathrm{C}$ until required. For additions to cell cultures, native hHGF was diluted in $0.2 \%$ BSA (Armour Pharmaceuticals, Eastbourne, Sussex).

Preparation of recombinant hHGF. Plasmid DNA pKCRHGF-2 containing two hHGF cDNA inserts (3) in the BamH1 cleavage site of pKCR (16) was transfected with plasmid pSV2 neo DNA (17) into $\mathrm{CHO}$ cells. The HGF expressing clone was selected after detection of HGF in the culture supernatants using an ELISA developed with native hHGF as standard (9). The cloned Chinese hampster ovary (CHO) cells (BD-24) were cultured in E-RDF medium (18) (Kyokuto Seiyaku, Tokyo) containing $10 \%$ FCS. The supernatant was chromatographed on a S-Sepharose Fast Flow (Pharmacia Inc., Piscataway, NJ) column and adsorbed recombinant hHGF protein eluted with $10 \mathrm{mM}$ sodium phosphate buffer ( $\mathrm{pH} 7.5$ ) containing $0.7 \mathrm{M} \mathrm{NaCl}$. The hHGF fraction was analyzed by SDS polyacrylamide gel electrophoresis. For addition to cell cultures, recombinant hHGF was diluted in $1 \%$ BSA.

Preparation of adult rat hepatocytes. Hepatocytes were isolated from $200 \mathrm{~g}$ male Wistar rats by the established two-stage collagenase perfusion technique as described in detail elsewhere (19).

Preparation of adult human hepatocytes. Normal human liver tissue was obtained from segments surgically removed from adult donor organs before reduced-graft transplant into pediatric recipients. Tissue had been perfused free of blood with University of Wisconsin preservation fluid (20) and maintained at $4^{\circ} \mathrm{C}$ for $12-24 \mathrm{~h}$ before cell isolation.

Hepatocytes were isolated by enzyme perfusion originally described for use with human liver by Strom et al. (21) with several modifications. Two exposed vessels on the single cut surface of $100-200 \mathrm{~g}$ segments from the right or the left lobe were cannulated with $3 \mathrm{~mm}$ internal diameter tubing. Other major vessels were sutured and the tissue was perfused at $50 \mathrm{ml} / \mathrm{min}$ sequentially with $750 \mathrm{ml} \mathrm{Ca}{ }^{2+} / \mathrm{Mg}^{2+}$-free Krebs ringer bicarbonate buffer containing $10 \mathrm{mM}$ Hepes (KRB), 1500 $\mathrm{ml} 0.5 \mathrm{mM}$ EGTA in KRB and $750 \mathrm{ml} \mathrm{KRB}$. Perfusates were allowed to run to waste. Finally, $200 \mathrm{ml}$ enzyme solution $(0.05 \%$ collagenase, $0.05 \%$ hyaluronidase, $0.1 \%$ dispase, $0.005 \%$ DNAase containing $5 \mathrm{mM}$ $\mathrm{CaCl}_{2}$ ) was perfused with recirculation and enzymatic digestion continued for 30-45 min until the liver was judged to be substantially softened. The tissue was then minced with scissors in $500 \mathrm{ml} \mathrm{KRB}$, containing $\mathrm{CaCl}_{2}$ and $10 \% \mathrm{FCS}$, stirred for $10 \mathrm{~min}$, and the cell suspension filtered through $60 \mu \mathrm{m}$ nylon mesh. Cells were washed $3 \times$ in KRB/ $\mathrm{CaCl}_{2} / 10 \% \mathrm{FCS}$ by centrifugation at $50 \mathrm{~g}$, and viability and yield assessed by trypan blue exclusion and haemocytometer counting. All solutions were supplemented with $100 \mathrm{U} / \mathrm{ml}$ pencillin and $100 \mu \mathrm{g} / \mathrm{ml}$ streptomycin, were pregassed with $95 \% \mathrm{O}_{2} / 5 \% \mathrm{CO}_{2}$, and maintained at $37^{\circ} \mathrm{C}$ throughout.

Culture of hepatocytes. Rat and human hepatocytes were plated on rat-tail tendon collagen-coated $35 \mathrm{~mm}$ tissue culture dishes (22) in $2 \mathrm{ml}$ of $\mathrm{KRB} / \mathrm{CaCl}_{2} / 10 \% \mathrm{FCS}\left(1.5 \times 10^{5}\right.$ and $3 \times 10^{5}$ cells $/ \mathrm{ml}$, respectively $)$ After $60 \mathrm{~min}$, attached cells were washed $2 \times \mathrm{PBS}$ and were refed with arginine-free Williams' $E$ medium supplemented with $0.4 \mathrm{mM}$ ornithine, $100 \mathrm{nM}$ insulin, $5.5 \mu \mathrm{M}$ hydrocortisone, $100 \mathrm{U} / \mathrm{ml}$ penicillin, and $100 \mu \mathrm{g} / \mathrm{ml}$ streptomycin without serum (19). Medium with appropriate hormonal and growth factor additions was replenished every 24 h. For determination of DNA synthesis, $\left[{ }^{3} \mathrm{H}\right]$-thymidine $(1 \mu \mathrm{Ci} / \mathrm{ml})$ was added for the final $24 \mathrm{~h}$ in culture, and incorporation measured directly in hydrolyzed DNA extracts (19) or by autoradiography (22). Data are presented as means \pm standard deviations of triplicate cultures from representative hepatocyte cultures. Each experiment was repeated with hepatocytes from at least three separate preparations. For determination of S-phase labeling index, a minimum of 100 cells were scored in at least five randomly chosen fields on each plate. Data represent the mean of duplicate cultures. The presence of small numbers of nonparenchymal cells was noted in both rat and human cultures correspond- ing to less than $2 \%$ of the total cell number. After autoradiography, careful screening showed that these cells did not proliferate under the culture conditions employed.

\section{Results}

Expression of recombinant $h H G F$. Supernatants from $\mathrm{CHO}$ transfectants were chromatographed on S-Sepharose Fast Flow columns and hHGF activity was eluted with $10 \mathrm{mM}$ sodium phosphate buffer ( $\mathrm{pH} \mathrm{7.5)} \mathrm{containing} 0.7 \mathrm{M} \mathrm{NaCl}$. The final preparation showed two bands of mol wt $\sim 86,600$ and 80,900 on SDS-PAGE under nonreducing conditions (Fig. 1). These molecular weights correspond to native hHGF which we reported previously (2) and both showed hHGF activity. The apparent heterogeneity of recombinant hHGF may be due to differences in glycosylation. Under reducing conditions, the two bands separated into four of mol wt 62,800 and 58,100 corresponding to the heavy chain and mol wt 34,300 and 31,800 corresponding to the light chain (Fig. 1).

Stimulation of DNA synthesis in rat hepatocytes by hHGF. The bioactivity of recombinant hHGF was tested by its ability to stimulate $\left[{ }^{3} \mathrm{H}\right]$-thymidine incorporation into normal adult rat hepatocytes and compared directly with a preparation of native hHGF. As shown in Fig. 2, the dose-response curves for native and recombinant were almost identical with significant increases from $0.63 \mathrm{ng} / \mathrm{ml}$ and reaching maximal activity at 10 $\mathrm{ng} / \mathrm{ml}$. Solvent controls (addition of $0.2 \%$ or $1 \%$ BSA for native and recombinant hHGF groups, respectively) gave rates of incorporation no higher than with basal medium (results not shown). The S-phase labeling index showed a similar pattern of incorporation (Fig. 3). Up to $30 \%$ of hepatocytes became labeled during the 24 -h thymidine incubation period in the presence of the highest dose of recombinant hHGF compared with

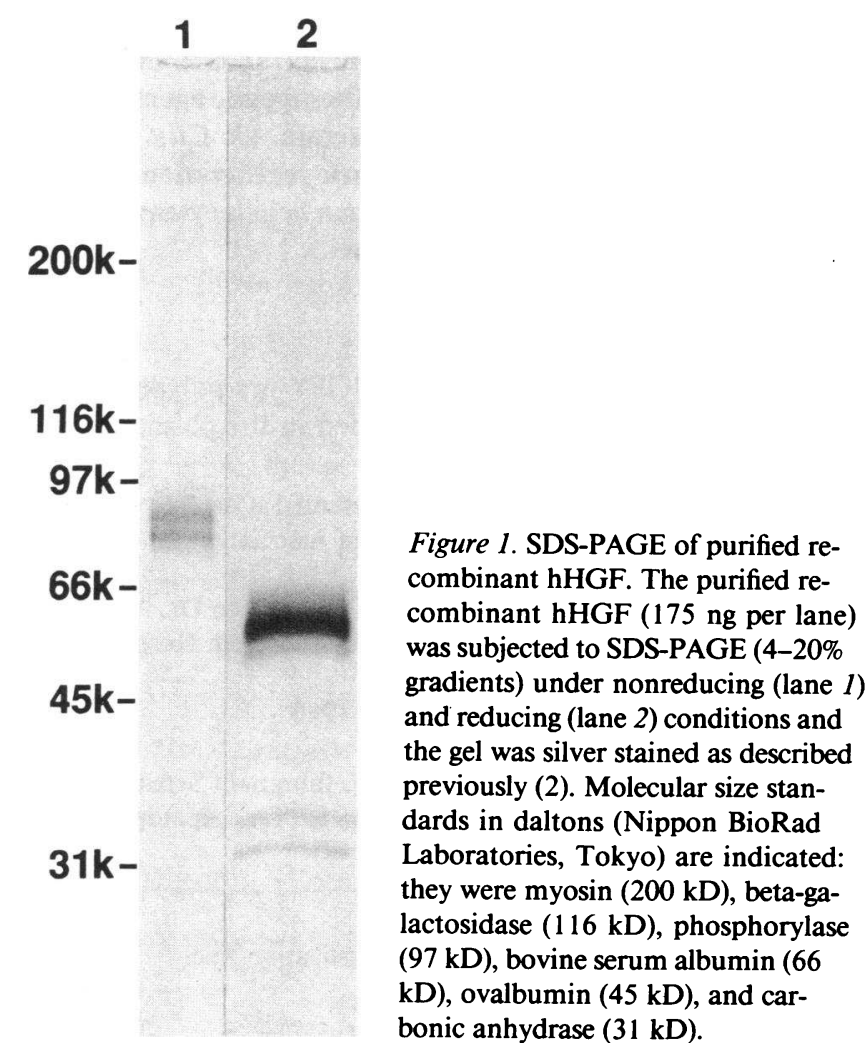




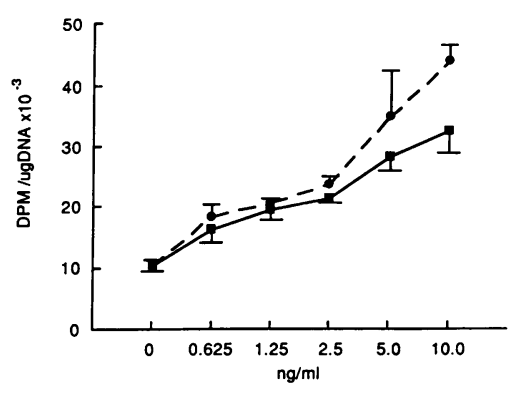

dium was changed daily and $\left[{ }^{3} \mathrm{H}\right]$-thymidine added for the final $24 \mathrm{~h}$. The concentrations of native and recombinant hHGF were determined by ELISA (9). Results are presented as mean \pm standard deviation of triplicate cultures.

$22 \%$ of native hHGF. Careful scrutiny of cultures after autoradiography revealed the presence of numerous hepatocytes undergoing mitosis (not shown).

Stimulation of DNA synthesis in human hepatocytes by $h H G F$. Results of cell preparations from individual human liver perfusions are summarized in Table I. Viability of preparations was consistently $80 \%$ or above. Although the yield/g wet wt tissue was relatively low, the amount of liver tissue perfused gave total yields in excess of $10^{9}$ cells.

Fig. 4 shows a typical dose-response curve of native and recombinant hHGF on human hepatocyte DNA synthesis. Although the overall rate of basal $\left[{ }^{3} \mathrm{H}\right]$-thymidine incorporation into DNA was lower than seen in rat cells (Figs. 2 and 4), reflected also by a lower basal S-phase labeling index (Figs. 3 and 5), the degree of stimulation by HGF was similar. Moreover, human hepatocytes appeared more sensitive to hHGF than rat cells with half-maximal stimulatory concentration of native and recombinant hHGF on human hepatocytes $(0.6 \mathrm{ng} /$ $\mathrm{ml}$ and $0.3 \mathrm{ng} / \mathrm{ml}$, respectively) consistently lower than rat cells $(\sim 2 \mathrm{ng} / \mathrm{ml})$. These observations were confirmed by autoradiography and determination of S-phase labeling index (Fig. 5) with maximal stimulation (up to $20 \%$ ) of labeled cells occurring at $1.2 \mathrm{ng} / \mathrm{ml}$ recombinant $\mathrm{hHGF}$ and at $5 \mathrm{ng} / \mathrm{ml}$ native hHGF.

\section{Discussion}

Previous studies have shown that purified native hHGF can stimulate DNA synthesis in primary cultures of rat hepatocytes

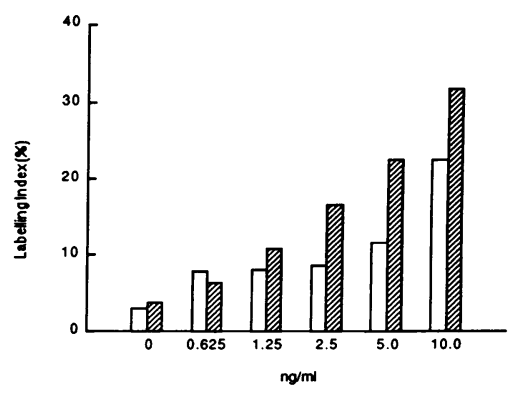

Figure 3. Effect of native and recombinant hHGF on the S-phase nuclear labeling index of primary rat hepatocytes. Hepatocytes were maintained in culture for $72 \mathrm{~h}$ in serum-free Williams' medium supplemented with native hHGF (clear bars) or recombinant hHGF

(cross-hatched bars). Cells were refed every $24 \mathrm{~h},\left[{ }^{3} \mathrm{H}\right]$-thymidine added for the final day, and plates processed for autoradiography. Percentage of labeled cells was determined by counting a minimum of 100 cells in five random fields per dish. Each bar represents the mean of duplicate cultures.
Table 1. Preparation of Hepatocytes from Adult Human Liver

\begin{tabular}{rccc}
\hline HLP & Weight & Viability & Yield \\
\hline & $g$ & $\%$ & cells $\times 10^{-6} / g$ \\
6 & 105 & 80 & 2.74 \\
9 & 105 & 93 & 1.90 \\
10 & 205 & 90 & 5.05 \\
14 & 120 & 82 & 3.91 \\
15 & 100 & 90 & 2.00 \\
16 & 165 & 84 & 2.10
\end{tabular}

Results from six separate human liver perfusions $(H L P)$ are shown with yield of cells and viability, as determined by trypan blue dye exclusion, indicated.

$(2,15)$ with half-maximal stimulation at $1-2 \mathrm{ng} / \mathrm{ml}$ (equivalent to $\sim 10 \mathrm{pM})$. The dose responses of hHGF described here are in close agreement. We have also shown that recombinant hHGF derived from a CHO-cell transfectant displays full biological activity and is at least as potent as the native form. To our knowledge this is the first demonstration of a biologically active recombinant form of the hepatocyte growth factor on isolated primary hepatocyte cultures.

Our data also indicate that human hepatocytes are more responsive to both native and recombinant hHGF than are rat cells with significant activity in the low picomolar range. Recombinant hHGF is capable of elliciting a growth response below $0.3 \mathrm{ng} / \mathrm{ml}$ (equivalent to $3 \mathrm{pM}$ ). With the half-maximal stimulatory concentrations of factors including EGF, TGF $\alpha$, and aFGF in the range of $0.1-5 \mathrm{nM}$ on isolated primary hepatocyte cultures $(19,23,24)$, on a molar basis hHGF is, therefore, the most potent growth factor for isolated hepatocytes yet described. The presence of numerous mitotic cells also indicates that HGF is capable of acting as a true mitogenic factor. HGF can, therefore, be considered as a primary mitogen (25) since it retains full biological activity in the absence of other growth factors.

Our recent investigations using normal adult human hepatocyte cultures have indicated that they retain biological responsiveness to several of the factors known to be active on rat cells, including EGF, TGF $\alpha$, and TGF $\beta$ (26). However, important species differences have become apparent. For example AVP, which in the rat can enhance hepatocyte DNA synthesis both in vitro and in vivo $(27,28)$, fails to stimulate DNA synthesis in human hepatocytes, either alone or in the presence of other growth factors (29). Further studies revealed few if any functional V1 type specific AVP receptors present in human liver plasma membrane preparations or on freshly isolated hepato-

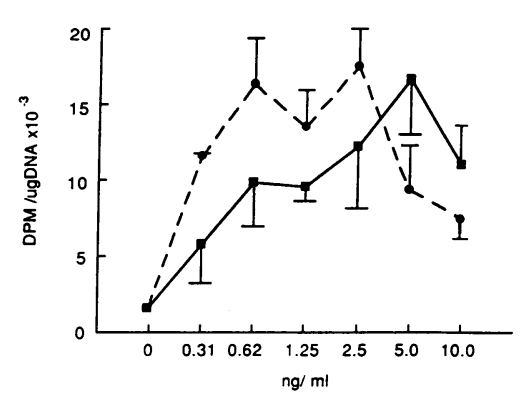

Figure 4. Effect of native and recombinant hHGF on DNA synthesis on primary cultures of adult human hepatocytes. Cultures were treated as described in the legend to Fig. 2. Each point represents the mean \pm standard deviation of triplicate cultures. 


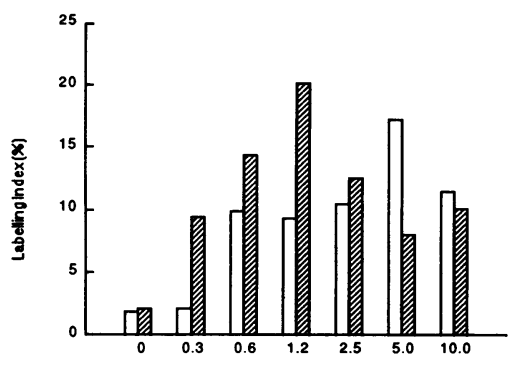

$\mathrm{ng} / \mathrm{ml}$
Figure 5. Effect of native and recombinant hHGF on S-phase nuclear labelling index of adult human hepatocytes. Cells were maintained in culture and treated as described in Fig. 3. Each bar represents the mean of duplicate cultures.

cytes (30). Specific V1 type receptors are also absent from rabbit liver (31). These observations highlight the care required when extrapolating from animal studies to the human situation, and emphasize the importance of the work described here using normal human hepatocytes in establishing the identity of the factors that may be of physiological relevance in control of human liver regeneration.

The availability of a bioactive recombinant human hepatocyte growth factor has important implications in the study of liver growth in vivo. Firstly, in vivo infusion studies are now feasible in order to test its biological activity in the intact, partially hepatectomized or hepatotoxin-treated animal. Secondly, it provides impetus to the possibility of manipulating the regenerative process in vivo and, therefore, providing a potential clinical therapeutic application. However, full regeneration of functional liver tissue requires not just expansion of the hepatocyte population, but growth of the other cell types present in the liver and deposition of extracellular matrix components, to form correct lobular architecture. Clearly the control mechanisms are complex and critically regulated and are therefore also likely to involve more than one individual factor. The demonstration in regenerating liver tissue of increased expression of several other factors capable of modulating cell growth and differentiation, including TGF $\alpha$, aFGF, and TGF $\beta(23$, $24,32,33$ ) reinforces this conclusion.

Although HGF expression in the liver does occur, it is not confined to this organ and its presence in other tissues both at the protein and mRNA levels has been shown $(5,6,10)$. The question, therefore, of whether intra- or extra-hepatic sources are responsible for the elevated circulating levels of HGF during hepatic regeneration $(11,12)$ has not yet been resolved. Nevertheless the ability of HGF to stimulate hepatocyte growth in the absence of other growth factors and the potency in vitro demonstrated here, suggest that it may make an important contribution to control of the growth process in vivo.

\section{Acknowledgments}

We are grateful to Dr. S. Iqbal and Dr. P. Burra for help with the preparation of human hepatocytes and to $D$. Anderson for technical support. We also thank Dr. Shin of Otsuka Assay Laboratories, Otsuka Pharmaceutical Co. Ltd., Japan for supplying ELISA kits to hHGF. This work was supported in part by grants from the Nuffield Foundation, the Wellcome Trust, and Grant-in-Aid for Cancer Research (No. 02152094) from the Ministry of Education, Science, and Culture of Japan.

\section{References}

1. Gohda, E., H. Tsubouchi, H. Nakayama, S. Hirono, K. Takahashi, M. Koura, S. Hashimoto, and Y. Daikuhara. 1986. Human hepatocyte growth factor

in plasma from patients with fulminant hepatic failure. Exp. Cell Res. 166:139150 .

2. Gohda, E., H. Tsubouchi, H. Nakayama, S. Hirono, O. Sakiyama, K. Takahashi, H. Miyazaki, S. Hashimoto, and Y. Daikuhara. 1988. Purification and partial characterization of hepatocyte growth factor from plasma of a patient with fulminant hepatic failure. J. Clin. Invest. 81:414-419.

3. Miyazawa, K., H. Tsubouchi, D. Naka, K. Takahashi, M. Okigaki, N. Arakaki, H. Nakayama, S. Hirono, O. Sakiyama, E. Gohda, Y. Daikuhara, and N. Kitamura. 1989. Molecular cloning and sequence analysis of cDNA for human hepatocyte growth factor. Biochem. Biophys. Res. Commun. 163:967-973.

4. Nakamura, T., T. Nishizawa, M. Hagiya, T. Seki, M. Shimonishi, A. Sugimura, K. Tashiro, and S. Shimizu. 1989. Molecular cloning and expression of human hepatocyte growth factor. Nature (Lond.) 342:440-443.

5. Tashiro, K., M. Hagiya, T. Nishizawa, T. Seki, M. Shimonishi, S. Shimizu, and T. Nakamura. 1990. Deduced primary structure of rat hepatocyte growth factor and expression of the mRNA in rat tissues. Proc. Natl. Acad. Sci. USA. $87: 3200-3204$.

6. Okajima, A., K. Miyazawa, and N. Kitamura, 1990. Primary structure of rat hepatocyte growth factor and induction of its mRNA during liver regeneration following hepatic injury. Eur. J. Biochem. 193:375-381.

7. Zarnegar, R., S. Muga, J. Enghild, and G. Michalopoulos. 1989. NH2-Terminal amino acid sequence of rabbit hepatopoietin A, A heparin-binding polypeptide growth factor for hepatocytes. Biochem. Biophys. Res. Commun. 163:13701376.

8. Tsubouchi, H., S. Hirono, E. Gohda, N. Nakayama, K. Takahashi, O. Sakiyama, H. Miyazaki, J. Sugihara, E. Tomita, Y. Muto, Y. Daikuhara, and S. Hashimoto. 1989. Clinical significance of human hepatocyte growth factor in blood from patients with fulminant hepatic failure. Hepatology (Baltimore). 9:875-881.

9. Tsubouchi, H., Y. Niitani, S. Hirono, H. Nakayama, E. Gohda, N. Arakaki, O. Sakiyama, K. Takahashi, M. Kimoto, S. Kawakami, M. Setoguchi, T. Tachikawa, S. Shin, T. Arima, and Y. Daikuhara. 1991. Levels of the human hepatocyte growth factor in serum of patients with various liver diseases determined by an enzyme-linked immunosorbent assay. Hepatology (Baltimore). 13: $1-5$.

10. Zarnegar, R., S. Muga, R. Rahija, and G. Michalopoulos. 1990. Tissue distribution of HPTA: a heparin-binding polypeptide growth factor for hepatocytes. Proc. Natl. Acad. Sci. USA. 87:1252-1256.

11. Michalopoulos, G., K. A. Houck, M. L. Dolan, and N. C. Luetteke. 1984 Control of hepatocyte replication by two serum factors. Cancer Res. 44:44144419.

12. Nakamura, T., K. Nawa, and A. Ichihara. 1984. Partial purification and characterization of hepatocyte factor from serum of hepatectomized rats. Biochem. Biophys. Res. Commun. 122:1450-1459.

13. Kinoshita, T., K. Tashiro, and T. Nakamura. 1989. Marked increase of HGF mRNA in non-parenchymal liver cells of rats treated with hepatotoxins. Biochem. Biophys. Res. Commun. 165:1229-1234.

14. Bucher, N. L. R., and A. J. Strain. 1991. Regulatory mechanisms in hepatic regeneration. In Wright's Textbook of Liver and Biliary Disease. $\mathbf{R}$ Wright, M. J. Arthur, and H. Millward-Sadler, editors. W. B. Saunders Co. Ltd., London. In press.

15. Nakamura, T., K. Nawa, A. Ichihara, N. Kaise, and T. Nishino. 1987 Purification and subunit structure of hepatocyte growth factor from rat platelets. FEBS (Fed. Eur. Biol. Soc.) Lett. 224:311-316.

16. O'Hare, K., C. Benoist, and R. Breathnach 1981. Transformation of mouse fibroblasts to methotrexate resistance by a recombinant plasmid expressing a prokaryotic dihydrofolate reductase. Proc. Natl. Acad. Sci. USA. 78:15271531 .

17. Southern, P. J., and P. Berg. 1982. Transformation of mammalian cells to antibiotic resistance with a bacterial gene under control of the SV40 early region promoter. J. Mol. Appl. Genet. 1:327-342.

18. Murakami, H. 1989. Serum-free media used for cultivation of hybridomas. Adv. Biotechnol. Processes. 11:107-141.

19. McGowan, J. A., A. J. Strain, and N. L. R. Bucher. 1981. DNA synthesis in primary cultures of adult rat hepatocytes in a defined medium: effects of epidermal growth factor, insulin, glucagon, and cyclic AMP. J. Cell. Physiol. 108:353-363.

20. Belzer, F. O., and J. H. Southard. 1988. Principles of Solid-Organ Preservation by Cold Storage. Transplantation 45:673-676.

21. Strom, S. C., R. L. Jirtle, R. S. Jones, D. L. Novicki, M. R. Rosenberg, A. Novotny, G. Irons, J. R. McLain, and G. Michalopoulos. 1982. Isolation, culture and transplantation of human hepatocytes. J. Natl. Cancer. Inst. 68:771-777.

22. Strain, A. J., J. A. McGowan, and N. L. R. Bucher, 1982. Stimulation of DNA synthesis in primary cultures of adult rat hepatocytes by rat platelet-associated substances. In Vitro. 18:108-116.

23. Mead, J. E., and N. Fausto. 1989. Transforming growth factor alpha may be a physiological regulator of liver regeneration by means of an autocrine mechanism. Proc. Natl. Acad. Sci. USA. 86:1558-1562.

24. Kan, M., J. Huang, P. E. Mansson, H. Yasumitsu, B. Carr, and W. L. 
McKeehan. 1989. Heparin-binding growth factor type 1 (acidic fibroblast growth factor): a potential biphasic autocrine and paracrine regulator of hepatocyte regeneration. Proc. Natl. Acad. Sci. USA. 86:7432-7436.

25. Fausto, N., and J. E. Mead. 1989. Regulation of liver growth: protooncogenes and transforming growth factors. Lab. Invest. 60:4-13.

26. Ismail, T., A. J. Strain, and P. McMaster. 1989. The role of transforming growth factors alpha and beta on DNA synthesis in normal adult human hepatocytes. Hepatology (Baltimore). 10:606a. (Abstr.)

27. Russell, W. E., and N. L. R. Bucher. 1983. Vasopressin as a regulator of liver growth. In Isolation, Characterization and use of Hepatocytes. R. A. Harris and N. W. Cornell, editors. Elsevier Science Publishing Co., New York. P171P176.

28. Russell, W. E., and N. L. R. Bucher. 1983. Vasopressin Modulates Liver Regeneration in the Brattleboro Rat. Am. J. Physiol. 245:G321-G324.
29. Ismail, T., D. Anderson, P. McMaster, and A. J. Strain. 1990. Arginine vasopressin and angiotension stimulate DNA synthesis in primary rat but not human hepatocytes. Hepatology (Baltimore). 12:913a. (Abstr.)

30. Howl, J., T. Ismail, A. J. Strain, and M. Wheatley. 1990. Do vasopressin receptors have a significant role in the hormonal regulation of human liver function? Biochem. Soc. Trans. 18:399-400.

31. Vandekerckhove, A., F. Miot, S. Keppens, and H. DeWulf. 1989. Lack of $V_{1}$ vasopressin receptors in rabbit hepatocytes. Biochem. J. 259:609-611.

32. Braun, L, J. E. Mead, Panzica, R. Mikumo, G. I. Bell, and N. Fausto. 1988. Transforming growth factor $\beta$ mRNA increases during liver regeneration: a possible paracrine mechanism of growth regulation. Proc. Natl. Acad. Sci. USA. 85:1539-1543.

33. Strain, A. J. 1988. Transforming growth factor $-\beta$ and inhibition of hepatocellular proliferation. Scand. J. Gastroenterol. 23:(Suppl)37-45. 